\title{
Passivation of Aluminum in Lithium-ion Battery Electrolytes with LiBOB
}

\author{
Xueyuan Zhang ${ }^{1}$ and Thomas M. Devine ${ }^{1,2}$ \\ ${ }^{1}$ Lawrence Berkeley National Laboratory \\ Energy, Environment and Technology Division \\ Berkeley, CA \\ ${ }^{2}$ Department of Materials Science and Engineering \\ University of California \\ Berkeley, CA 94720
}

\begin{abstract}
A combination of cyclic polarization tests, electrochemical impedance spectroscopy, and electrochemical quartz crystal microbalance (EQCM) measurements indicate a film is formed when aluminum is polarized above $4.5 \mathrm{~V}$ in $1: 1 \mathrm{EC}+\mathrm{DMC}$ with $1 \mathrm{M} \mathrm{LiBOB}$. The quantity of film that is formed increases with increasing applied potential. Results of EQCM tests suggest the film is $\mathrm{AlBO}_{3}$. The film is very protective against corrosion and inhibits pitting corrosion of aluminum in normally corrosive 1M LiTFSI.
\end{abstract}

\section{Introduction}

Although $\mathrm{LiPF}_{6}$ is used in commercially available lithium-ion battery electrolytes, $\mathrm{LiPF}_{6}$ does have some shortcomings. In particular, the thermal decomposition ${ }^{1-3}$ of $\mathrm{LiPF}_{6}$ and 
its hydrolysis ${ }^{4}$ in the presence of water contamination generate toxic and corrosive products. These products can dissolve the battery's cathode and corrode the cathode's aluminum current collector. The salt known as LiBOB (lithium bis-oxalato borate) might serve as a suitable replacement for $\mathrm{LiPF}_{6}{ }^{5,6} \mathrm{LiBOB}$ has reasonable solubility and electrolytes composed of LiBOB dissolved in mixtures of linear plus cyclized carbonates exhibit good electrical conductivity. In addition, $\mathrm{LiBOB}$ has much greater thermal stability than $\mathrm{LiPF}_{6}$.

The passivation of aluminum in battery electrolytes with $\mathrm{LiPF}_{6}$ is another favorable characteristic of $\mathrm{LiPF}_{6}$. Results presented by Xu et al. ${ }^{6}$ indicate aluminum passivates in 1:1 EC+EMC with $1 \mathrm{~m}$ LiBOB. The present paper investigates the passive film formed on aluminum in 1:1 EC+DMC with $1 \mathrm{M} \mathrm{LiBOB}$ and demonstrates the corrosion resistance of aluminum protected by the film formed in LiBOB

\section{Experimental Procedure}

\section{Electrolytes and Samples}

Tests were conducted in electrolytes made of 1:1 (by volume) ethylene carbonate (EC, $99.95 \%)+$ dimethyl carbonate (DMC, 99.98\%) with four different combinations of the salts LiBOB and LiTFSI: (a) $1 \mathrm{M}$ LiBOB, (b) $1 \mathrm{M}$ LiTFSI, (c) $0.1 \mathrm{M} \mathrm{LiBOB}+0.9 \mathrm{M}$ LiTFSI, and (d) $0.02 \mathrm{M} \mathrm{LiBOB}+0.98 \mathrm{M}$ LiTFSI. EC and DMC were purchased from Ferro Corporation (Pharmaceuticals and Fine Chemicals). The salts LiBOB (99.99\%) and lithium (bis) trifluoromethanesulfonimide (LiTFSI) were obtained from Chemetall 
and 3M, respectively. Each electrolyte was prepared in a dry and deoxygenated glove box by mixing the above chemicals in their as received conditions.

With the exception of electrochemical quartz crystal microbalance (EQCM) measurements, all tests were conducted on samples of $25 \mu \mathrm{m}$ thick aluminum foil (98.5\%; main impurities are iron and silicon) obtained from Reynolds. EQCM experiments were conducted on one micron thick films of aluminum that were sputter deposited onto titanium-coated, $5 \mathrm{MHz}$ quartz crystals and purchased from Maxtek, Inc. Prior to testing, the surfaces of all aluminum samples were rinsed with acetone.

\section{$\underline{\text { Electrochemical Measurements }}$}

Cyclic polarization curves $(\mathrm{CyP})$ and electrochemical impedance spectra (EIS) were measured for circular aluminum foil samples with a surface area of $0.5 \mathrm{~cm}^{2}$ in a threeelectrode Teflon cell with an electrolyte volume of $3 \mathrm{cc}$, a $\mathrm{Li} / \mathrm{Li}^{+}$reference electrode, and a lithium counter electrode, . Lithium for the counter and reference electrodes was purchased from Cyprus Foote Mineral Company.

CyP curves were obtained by cycling the aluminum sample's potential at a rate of $5 \mathrm{mV} / \mathrm{s}$ between a lower limit of $2.5 \mathrm{~V}$ vs $\mathrm{Li} / \mathrm{Li}^{+}$and a maximum value, which ranged from 5.0 to 6.5V. CyP curves were generated with a Gamry potentiostat (Model PCI 4/750)

Electrochemical impedance spectra (EIS) were measured at corrosion potential and at applied potentials of $4.5 \mathrm{~V}, 5.5 \mathrm{~V}$ and $6.5 \mathrm{~V}$ in $1: 1 \mathrm{EC}+\mathrm{DMC}$ with $1 \mathrm{M} \mathrm{LiBOB}$. 
Electrochemical impedance was measured as a function of frequency by applying to the DC polarized aluminum sample a $\pm 20 \mathrm{mV}$ volt signal that varied sinusoidally with time over the frequency range from $10 \mathrm{KHz}$ to $0.01 \mathrm{~Hz}$.

Mass change measurements were made of one-micron thick aluminum samples sputterdeposited onto 5MHz quartz crystals. The EQCM (Model RQCM) was manufactured by Maxtek, Inc. The polarization curves were measured at sweep rate of $5 \mathrm{mV} / \mathrm{s}$. A Gamry Potentiostat controlled the sample's potential. Lithium from Alfa Chemical was used for reference and counter electrodes.

After electrochemical testing, the aluminum samples were examined with an optical microscope (50x-500x) for evidence of corrosion.

\section{Results}

Figures $1(a, b)$ present concurrent measurements of the oxidation current density and change in mass of aluminum during three successive cyclic polarization scans between $1.8 \mathrm{~V}$ and $5.5 \mathrm{~V}$ in $1: 1 \mathrm{EC}+\mathrm{DMC}$ with $1 \mathrm{M} \mathrm{LiBOB}$. The tests were conducted on a thin layer of aluminum that was sputtered deposited onto a quartz crystal.

The potential affected both the current density and the mass of aluminum especially during the first polarization cycle. The oxidation rate (current density) was very low and independent of potential between $1.8 \mathrm{~V}$ and $4.25 \mathrm{~V}$. The low oxidation rate is attributed to the protection provided by aluminum's air-formed oxide film. At $4.25 \mathrm{~V}$ the current 
density abruptly increased and reached a maximum at $4.8 \mathrm{~V}$. Between $4.8 \mathrm{~V}$ and $5.5 \mathrm{~V}$ the current density slowly decreased and then sharply decreased as the direction of potential change was reversed. The current density dropped below $1 \mu \mathrm{A} / \mathrm{cm}^{2}$ when the potential reached $5.0 \mathrm{~V}$. The current density was lower during the reverse scan than during the forward scan. As a result, a noticeable hysteresis was present in the first cyclic polarization curve.

The potential-driven changes in current density during the first scan correlated with changes in the mass of the aluminum. In particular, at $4.5 \mathrm{~V}$, there was an upsurge in the rate of mass increase. The upsurge in mass increase occurred in between the abrupt increase in current density at $4.25 \mathrm{~V}$ and the slow rate of decrease in current density that started at $4.8 \mathrm{~V}$. The high rate of mass increase continued as the potential was decreased from $5.5 \mathrm{~V}$ to $5.0 \mathrm{~V}$, during which the current density decreased at a very high rate. As the potential was lowered below $5.0 \mathrm{~V}$ the rate of mass increase and the current density decreased to their lowest values.

During the second and third polarization cycles, the current densities were much lower and there was only a very small hysteresis in the second cyclic polarization curve and approximately no hysteresis in the third cyclic polarization curve.

The very small hysteresis in the second polarization cycle and the absence of a hysteresis in the third polarization cycle were associated with a small increase in mass and a very small increase in mass, respectively. 
The increase in mass during the first polarization scan combined with the hysteresis in the first cyclic polarization scan indicate that a surface film was formed on top of the airformed oxide during anodic polarization and that the surface film inhibited further oxidation of aluminum. In the three polarization scans, there was a correlation between the magnitude of the current density and the mass increase. The results indicate that most of the film was formed during the forward portion of the first polarization cycle. Very little, if any, film growth occurred during the third cycle.

Figure 2(a,b) shows the response of the same aluminum sample to a second set of cyclic polarization scans. In the second set of scans the maximum potential was raised to $6.5 \mathrm{~V}$. The oxidation rate sharply increased during the first scan starting at a potential of $5.25 \mathrm{~V}$, which was close to the maximum potential of $5.5 \mathrm{~V}$ employed in the first set of scans. As was the case in the first set of scans, the first cyclic polarization curve of the second set of scans exhibited a noticeable hysteresis. The second and third cyclic polarization curves did not show a hysteresis. The concurrent measurement of mass change indicates film growth resumed when the potential was increased above $5.5 \mathrm{~V}$ and film growth continued until the potential during the reverse scan reached $6.2 \mathrm{~V}$. The oxidation current at $6.2 \mathrm{~V}$ during the reverse scan was approximately $3 \mu \mathrm{A} / \mathrm{cm}^{2}$ and was decreasing, eventually reaching a value well below $1 \mu \mathrm{A} / \mathrm{cm}^{2}$ by the time the potential was lowered to $5.7 \mathrm{~V}$. In the three polarization cycles between $1.8 \mathrm{~V}$ and $6.5 \mathrm{~V}$, most of the film growth occurred during the forward portion of the first polarization cycle. 
Following the two sets of cyclic polarizations, the aluminum sample was removed from the cell and examined with a light microscope (50X-500X). No evidence of either uniform corrosion or pitting corrosion was detected.

In summary, the results of the first set of cyclic polarization scans suggest that polarizing aluminum above $4.5 \mathrm{~V}$ resulted in a corrosion product layer that formed on top of aluminum's air-formed oxide. The amount of film formed depended strongly on potential. To substantially increase the amount of film, it was necessary to apply a higher potential than the sample had previously experienced. For this reason, a hysteresis in the cyclic polarization curve only occurred during the first scan. Subsequent cyclic polarization curves exhibit significant hysteresis only if the maximum potential was raised.

Results similar to those in Figures 1a and 2a were obtained for samples of $25 \mu \mathrm{m}$ thick aluminum foil. The electrochemical impedance spectra $(\log |Z|$ vs $\log ($ frequency)) of aluminum foil presented in Figure 3 support the idea that anodic polarization above approximately $4.5 \mathrm{~V}$ causes the formation of a surface film that inhibits further oxidation, and which grows when subjected to a higher anodic potential. The plot of $\log |\mathrm{Z}|$ vs $\log$ (frequency) between $0.03 \mathrm{~Hz}$ and $600 \mathrm{~Hz}$ is a straight line with a slope of -0.9 , suggesting that in this frequency range the dominant component of the system's equivalent circuit is a constant phase element (CPE). The impedance of the CPE is given by $\mathrm{Z}=(2 \pi \mathrm{fC})^{\alpha}$, with $\alpha=-0.9$, and $\mathrm{f}=$ frequency $\left(\mathrm{s}^{-1}\right)$ and $\mathrm{C}=$ capacitance. The impedance spectra at the open circuit potential (ocp) and at $4.5 \mathrm{~V}$ were identical, 
suggesting that the surface film at $4.5 \mathrm{~V}$ consisted of the air-formed oxide. Stepping the potential from $4.5 \mathrm{~V}$ to $5.5 \mathrm{~V}$ decreased the capacitance associated with the constant phase element from 2.76 to $2.27 \mu \mathrm{F} / \mathrm{cm}^{2}$. The capacitance was lowered further, from 2.27 to 1.98 , when the potential was stepped from $5.5 \mathrm{~V}$ to $6.5 \mathrm{~V}$. The decrease in capacitance is consistent with an increase in film thickness.

Additional experiments were conducted to determine the identity of the surface film that was formed during potentiodynamic polarization at potentials above $4.5 \mathrm{~V}$ and during potentiostatic polarization at $5.5 \mathrm{~V}$ and $6.5 \mathrm{~V}$. Unfortunately, FTIR spectroscopy was unsuccessful at identifying the air-formed oxide or the composite film consisting of the air-formed oxide plus the film that formed on top of the air-formed oxide during anodic polarization. Apparently, both the air-formed oxide and the composite film are too thin to produce infra-red spectra of measurable intensities.

Additional analyses of the EQCM data suggested the identity of the protective film that formed during anodic polarization in $1 \mathrm{M} \mathrm{LiBOB}$.

The ratio of the change in mass to the total amount of electric charge passed (mass per charge equivalent, mpe, has units of $\mathrm{g} / \mathrm{F}$ ) during the polarization cycles can help to identify the film that forms on the aluminum's surface. Table I summarizes the results of the two sets of polarization cycles presented in Figures 3 and 4 . Note that the mpe per cycle decreased as the number of cycles increased and that the mpe decreased as the maximum potential increased. One possible explanation for the decrease in mpe with increasing cycle number and increasing potential is the occurrence of a non film-forming oxidation reaction that accompanies the film formation. At low potentials, and during the 
first cycle, the film formation reaction is preferred. As the film grows, additional growth at the same value of potential is less likely and more of the oxidation occurs as oxidation of the electrolyte. The oxidation of the electrolyte also becomes more likely as the potential is raised.

Accordingly, the identity of the film is best determined by the mpe of the first cycle of the set of polarization cycles that ran between $1.8 \mathrm{~V}$ and $5.5 \mathrm{~V}$. Assuming that the film consists of components of the electrolyte, an mpe of $20 \mathrm{~g} / \mathrm{F}$ suggests that the film is made of aluminum borate: $\mathrm{AlBO}_{3}$, which has an mpe of $19.6 \mathrm{~g} / \mathrm{F}$. It is interesting to note that Zhuang et al. ${ }^{7}$ have identified $\mathrm{BO}_{3}$ components in the SEI formed on graphite anodes in PC with $1 \mathrm{~m}$ LiBOB.

During the second and third cycles between $1.8 \mathrm{~V}$ and $5.5 \mathrm{~V}$, and during cycling between $1.8 \mathrm{~V}$ and $6.5 \mathrm{~V}$, the mpe is less than $20 \mathrm{~g} / \mathrm{F}$ because film growth is accompanied by electrolyte oxidation.

The film formed on aluminum in LiBOB provides significant corrosion resistance as demonstrated by the film's ability to protect aluminum against corrosion by LiTFSI. Figure 4 shows the polarization curves of aluminum cyclically polarized between $1.8 \mathrm{~V}$ and 5.5V in 1:1 EC+DMC with 1M LiTFSI. During the first cycle, the oxidation current divided by the sample's area reached $0.7 \mathrm{~mA} / \mathrm{cm}^{2}$. The maximum oxidation rate increased to $1.2 \mathrm{~mA} / \mathrm{cm}^{2}$ and $1.5 \mathrm{~mA} / \mathrm{cm}^{2}$, respectively, during the second and third 
cycles. As shown in Figure 5, the aluminum sample was severely pitted during the cyclic polarizations.

In contrast to the severe pitting corrosion by LiTFSI of aluminum coated only by its airformed oxide, a sample of aluminum that was first passivated by three cyclic polarizations between $1.8 \mathrm{~V}$ and $6.0 \mathrm{~V}$ in $1: 1 \mathrm{EC}+\mathrm{DMC}$ with $1 \mathrm{M}$ LiBOB (see Figure 6a) was resistant to pitting corrosion when cyclically polarized in 1:1 EC+DMC with $1 \mathrm{M}$ LiTFSI. As shown in Figure 6b, the film formed in $1 \mathrm{M} \mathrm{LiBOB}$ is able to reduce the maximum rate of oxidation during the first scan by a factor of 35 . The maximum rate of oxidation is decreased with increasing number of cycles. The ratio of maximum oxidation rate during the third cycle of a sample protected by only its air-formed oxide (see Figure 5) and a sample protected by the combination of the air-formed oxide plus the passive film formed in $1 \mathrm{M} \mathrm{LiBOB}$ (see Figure 6b) was approximately 500. As shown in Figure 7, the number of pits is much lower and the sizes of the pits are much smaller in the sample that was prepassivated in $1 \mathrm{M} \mathrm{LiBOB}$.

A protective film formed on aluminum even in electrolytes with low concentrations of LiBOB and high concentrations of corrosive species such as LiTFSI. Figure 8 presents the cyclic polarization curves of aluminum polarized between $1.8 \mathrm{~V}$ and $5.5 \mathrm{~V}$ in $1: 1$ EC+DMC with a $1 \mathrm{M}$ mixed salt of 9:1 LiTFSI+LiBOB. A low concentration of $0.1 \mathrm{M}$ LiBOB was able to passivate aluminum and to protect the aluminum against corrosion by LiTFSI. No pits were found by optical microscopy of the sample of aluminum cyclically polarized in the electrolyte of 9:1 LiTFSI+LiBOB . 
Figure 9 indicates that $0.02 \mathrm{M}$ of $\mathrm{LiBOB}$ was nearly capable of completely preventing pit corrosion of aluminum in an electrolyte that also contained 0.98M LiTFSI. As shown in Figure 10, a few pits were formed but they did not grow very large. The pits were presumably formed during the first cycle, which exhibited the highest oxidation current. During the second and third cycles the oxidation rate was markedly lowered, suggesting that the pits had repassivated.

\section{Summary and Conclusions}

A combination of cyclic polarization curves, EIS and EQCM measurements indicate that a protective film is formed on aluminum in 1:1 $\mathrm{EC}+\mathrm{DMC}$ with $1 \mathrm{M} \mathrm{LiBOB}$. The rate of film growth decreases as the film thickens. Film growth is stimulated by raising the potential. During the first anodic scan to $5.5 \mathrm{~V}$, the increase in mass divided by the electrical charge passed (mpe) was $20.0 \mathrm{~g} / \mathrm{F}$ and suggested that the protective film was $\mathrm{AlBO}_{3}$. At high potentials $>5.5 \mathrm{~V}$ ), the mpe was less than approximately $15 \mathrm{~g} / \mathrm{F}$ and suggested that film growth is accompanied by electrolyte oxidation. The film formed on

$\mathrm{LiBOB}$ is very protective and was able to greatly restrict pitting corrosion of aluminum in 1M LiTFSI. The protective film was able to form in electrolytes with mixed salts of LiTFSI + LiBOB

\section{Acknowledgment}


This work was supported by the Assistant Secretary for Energy Efficiency and Renewable Energy, Office of FreedomCAR and Vehicle Technologies U.S. Department of Energy under Contract No. DE-AC03-76SF00098. 


\section{References}

1. S.E. Sloop, J.K. Pugh, S. Wang, J.B. Kerr, and K. Kinoshita, Electrochemical and Solid State Letts., 4, p. A42 (2001).

2. S.E. Sloop, J.B. Kerr, and K. Kinoshita, J. Power Sources, 119-121, p. 330 (2003).

3. C.G. Barlow, Electrochemical and Solid State Letts., 2, p. 362 (1999).

4. D. Guyomard and J.M. Tarascon, J. Power Sources, 54, p. 92 (1995).

5. Wu Xu and C. A. Angell, Electrochemical and Solid-State Letters, 4, E1-E4 (2001).

6. Kang Xu, Shengshui Zhang, T. Richard Jow, W. Xu, and C. Austen Angell, Electrochemical and Solid-State Letters, 5, A26-A29 (2002).

7. G.V. Zhuang, K. Xu, T.R. Jow, and P.N. Ross, Electrochemical and Solid-State Letters, 7, A224-A227 (2004). 


\section{Table I}

Ratio of Mass Change to Electrical Charge during Anodic Polarization of Aluminum in 1:1 EC+DMC with $1 \mathrm{M} \mathrm{LiBOB}$

$\begin{array}{lcc}\text { Voltage Range } & \text { Scan Number } & \text { Mass Change/Charge Passed }(\mathrm{g} / \mathrm{F}) \\ 1.8 \mathrm{~V}->5.5 \mathrm{~V} & 1 & 20.0 \\ 1.8 \mathrm{~V}->5.5 \mathrm{~V} & 2 & 15.4 \\ 1.8 \mathrm{~V}->5.5 \mathrm{~V} & 3 & 9.0 \\ & \\ 1.8 \mathrm{~V}->6.5 \mathrm{~V} & 4 & 13.8 \\ & \\ 1.8 \mathrm{~V}->6.5 \mathrm{~V} & 5 & 9.1 \\ 1.8 \mathrm{~V}->6.5 \mathrm{~V} & 6 & 9.0\end{array}$


Figure 1a. Three successive cyclic polarization curves of sputter-deposited thin film of aluminum in $1: 1 \mathrm{EC}+\mathrm{DMC}$ with $1 \mathrm{M} \mathrm{LiBOB}$. Potential was cycled between $1.8 \mathrm{~V}$ and $5.5 \mathrm{~V}$ vs $\mathrm{Li} / \mathrm{Li}^{+}$.

Figure $1 \mathrm{~b}$. Change in mass of sputter-deposited thin film of aluminum during the three successive cyclic polarization curves presented in Figure 1a. The lowest curve is for the first scan and the highest curve is for the third scan.

Figure 2a. Three successive polarization curves of sputter-deposited thin film of aluminum in 1:1 EC+DMC with $1 \mathrm{M} \mathrm{LiBOB}$. Potential was cycled between $1.8 \mathrm{~V}$ and $6.5 \mathrm{~V}$ vs. $\mathrm{Li}^{2} \mathrm{Li}^{+}$after the three cycles presented in Figure 1a.

Figure $2 b$. Change in mass of sputter-deposited thin film of aluminum during the three successive cyclic polarization curves presented in Figure 2a. The lowest curve is for the first scan and the highest curve is for the third scan.

Figure 3. Electrochemical impedance spectra of aluminum (98.5\%) after three successive cyclic polarizations in 1:1 EC+DMC with $1 \mathrm{M} \mathrm{LiBOB}$ from (1) $1.8 \mathrm{~V}$ to $4.5 \mathrm{~V}$ (see Figure 1a), (2) $1.8 \mathrm{~V}$ to $5.5 \mathrm{~V}$ (see Figure $1 \mathrm{~b}$ ), and (3) $1.8 \mathrm{~V}$ to $6.5 \mathrm{~V}$ (see Figure $1 \mathrm{c}$ ). 
Figure 4. Three consecutive cyclic polarization curves of aluminum in 1:1 EC+DMC with $1 \mathrm{M}$ LiTFSI. At high potentials, the oxidation rate increases with increasing number of cycles due pitting corrosion.

Figure 5. Optical micrograph of corrosion pits in surface of aluminum that was subjected to three cyclic polarization scans in 1:1 EC+DMC with 1M LiTFSI.

Figure 6a. Three consecutive cyclic polarization curves of aluminum in 1:1 EC+DMC with $1 \mathrm{M}$ LiBOB. At high potentials, the oxidation rate decreases with increasing number of cycles due to the formation of a protective film.

Figure 6b. Three consecutive cyclic polarization curves of prepassivated aluminum in 1:1 EC+DMC with $1 \mathrm{M}$ LiTFSI. The prepassivation treatment consisted of the three cyclic polarization scans presented in Figure 6a and produced a protective film.

Figure 7. Optical micrograph showing the small number of corrosion pits in surface of aluminum that was first passivated by three cyclic polarizations in 1:1 EC+DMC with $1 \mathrm{M} \mathrm{LiBOB}$ and then subjected to three cyclic polarization scans in 1:1 EC+DMC with $1 \mathrm{M}$ LiTFSI.

Figure 8. Three consecutive cyclic polarization curves of aluminum in 1:1 EC+DMC with 1M mixture of 9:1 LiTFSI+LiBOB. 
Figure 9. Three consecutive cyclic polarization curves of aluminum in 1:1 EC+DMC with 1M mixture of 98:2 LiTFSI+LiBOB.

Figure 10. Optical micrograph of surface of aluminum that was subjected to three cyclic polarization scans in 1:1 EC+DMC with 1M mixture of 98:2 LiTFSI+LiBOB. 


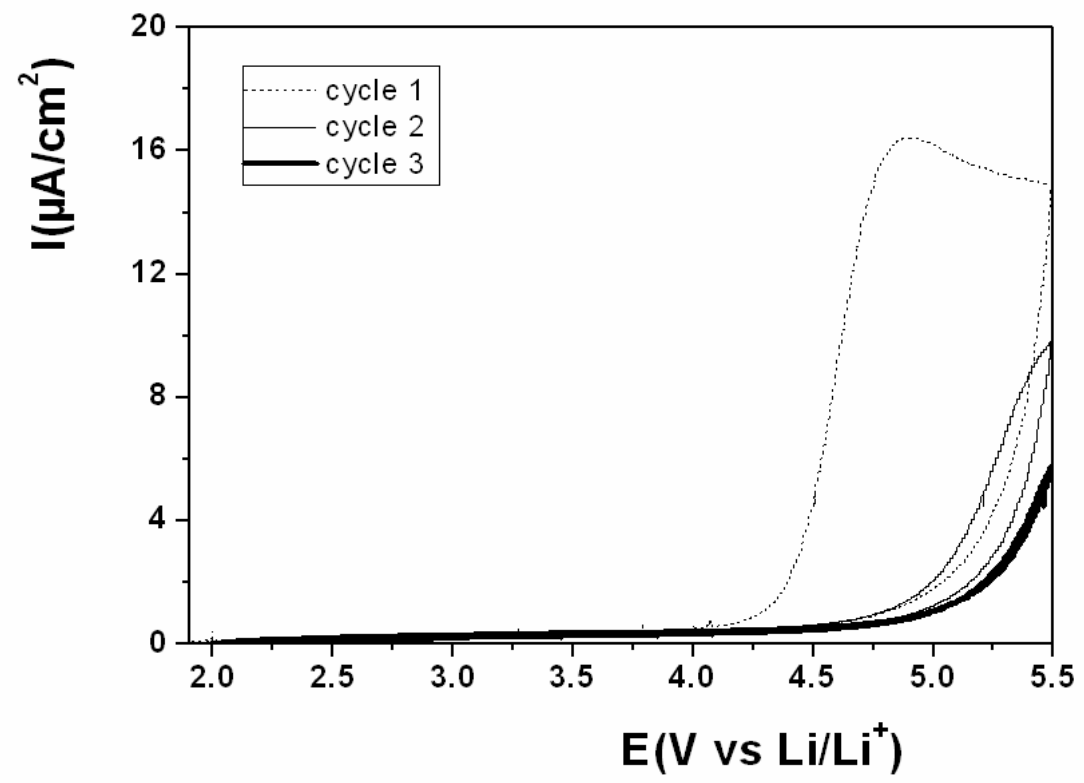

Figure 1a. Three successive cyclic polarization curves of sputter-deposited thin film of aluminum in $1: 1 \mathrm{EC}+\mathrm{DMC}$ with $1 \mathrm{M} \mathrm{LiBOB}$. Potential was cycled between $1.8 \mathrm{~V}$ and $5.5 \mathrm{~V}$ vs $\mathrm{Li} / \mathrm{Li}^{+}$. 


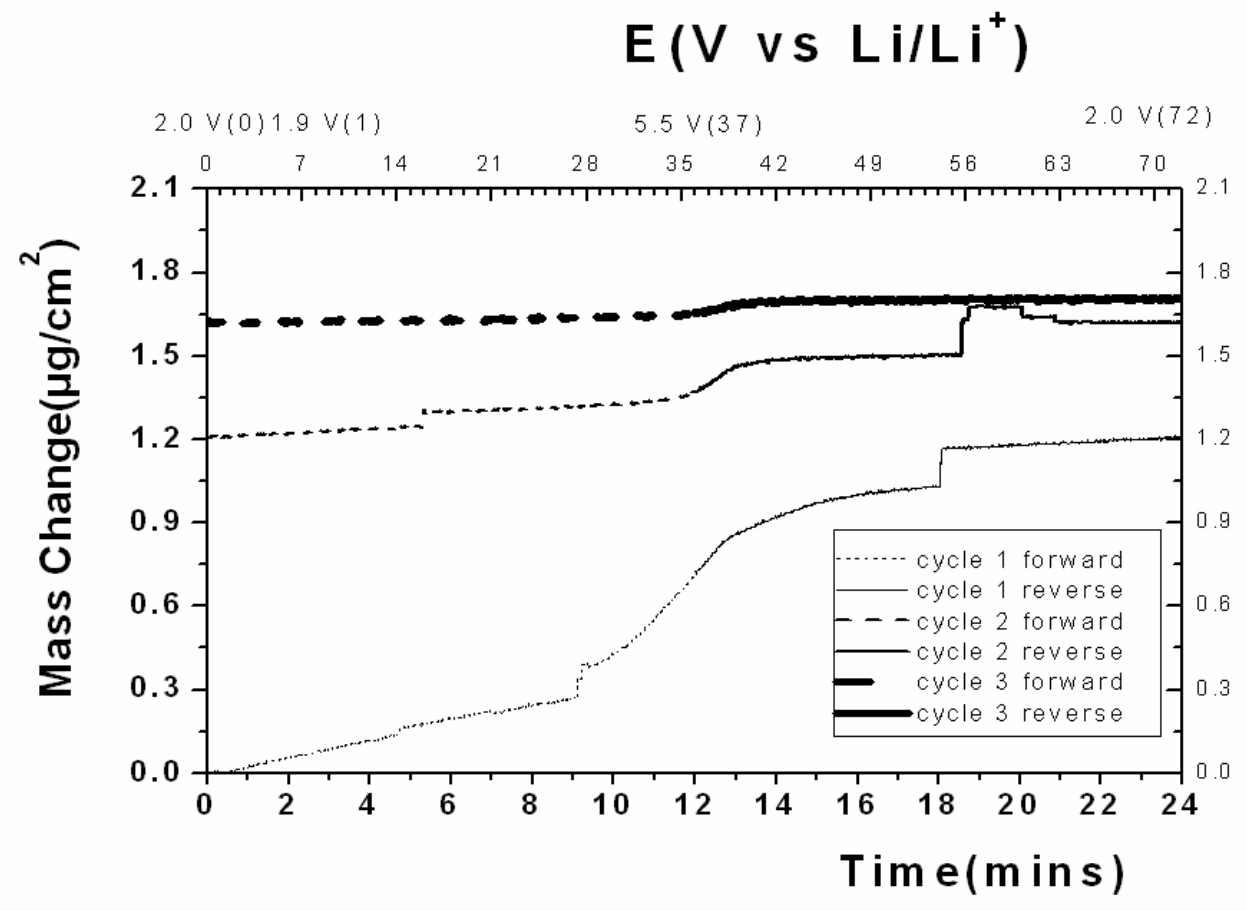

Figure 1b. Change in mass of sputter-deposited thin film of aluminum during the three successive cyclic polarization curves presented in Figure 1a. The lowest curve is for the first scan and the highest curve is for the third scan. 


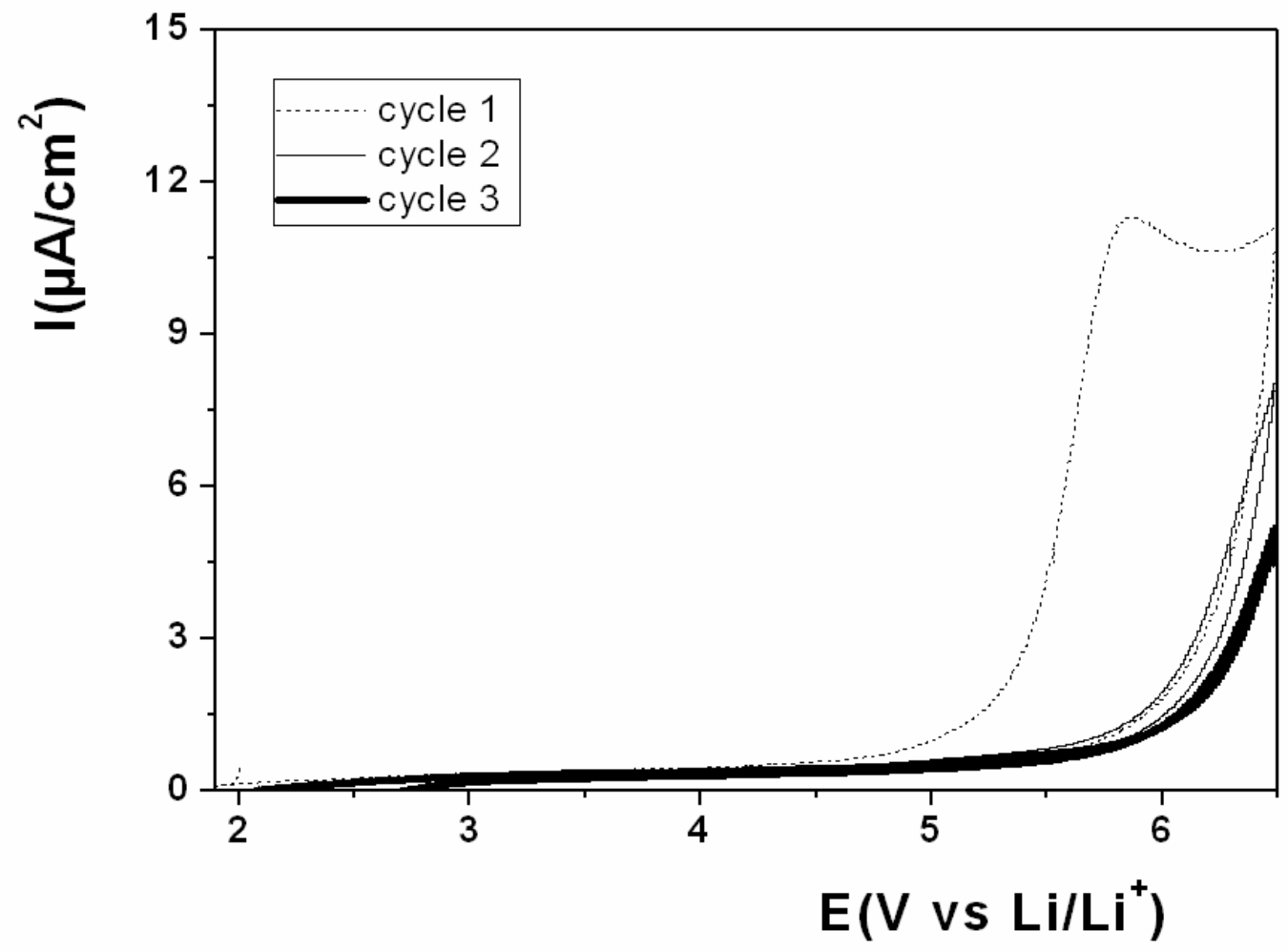

Figure 2a. Three successive polarization curves of sputter-deposited thin film of aluminum in 1:1 EC+DMC with $1 \mathrm{M} \mathrm{LiBOB}$. Potential was cycled between $1.8 \mathrm{~V}$ and $6.5 \mathrm{~V}$ vs. $\mathrm{Li}^{2} \mathrm{Li}^{+}$after the three cycles presented in Figure 1a. 


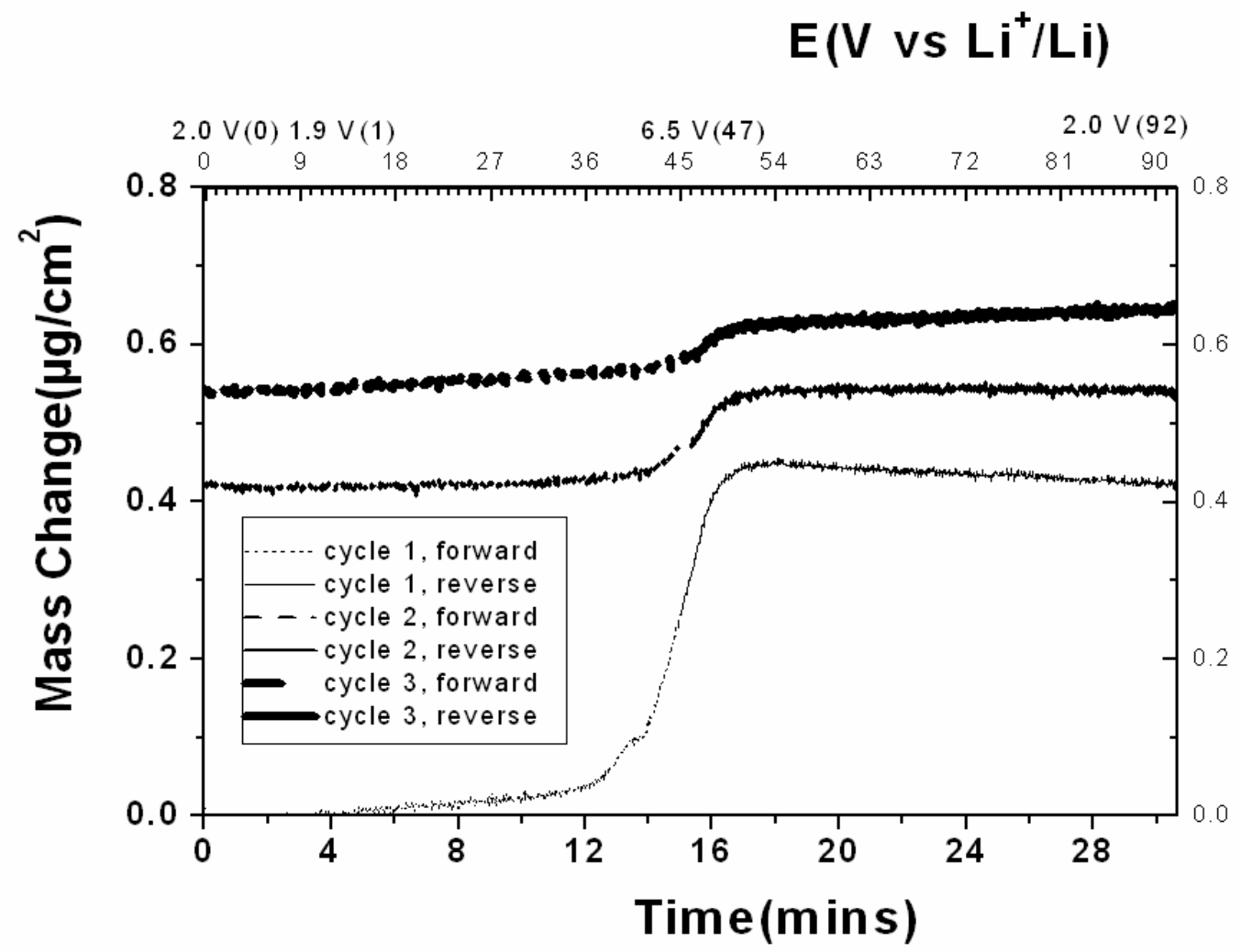

Figure $2 \mathrm{~b}$. Change in mass of sputter-deposited thin film of aluminum during the three successive cyclic polarization curves presented in Figure 2a. The lowest curve is for the first scan and the highest curve is for the third scan. 


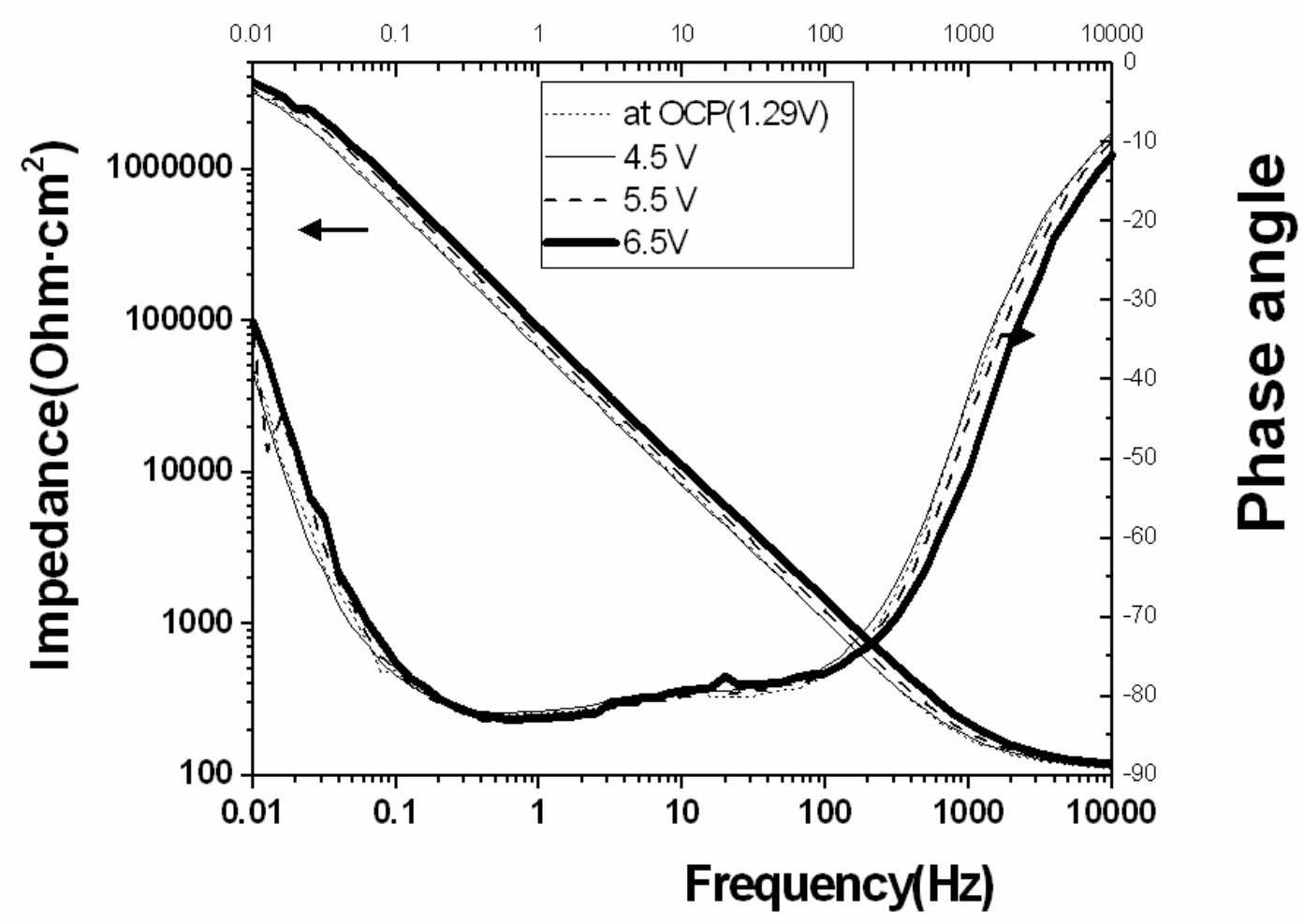

Figure 3. Electrochemical impedance spectra of aluminum (98.5\%) after three successive cyclic polarizations in 1:1 EC+DMC with $1 \mathrm{M} \mathrm{LiBOB}$ from (1) $1.8 \mathrm{~V}$ to $4.5 \mathrm{~V}$ (see Figure 1a), (2) $1.8 \mathrm{~V}$ to $5.5 \mathrm{~V}$ (see Figure $1 \mathrm{~b}$ ), and (3) $1.8 \mathrm{~V}$ to $6.5 \mathrm{~V}$ (see Figure 1c). 


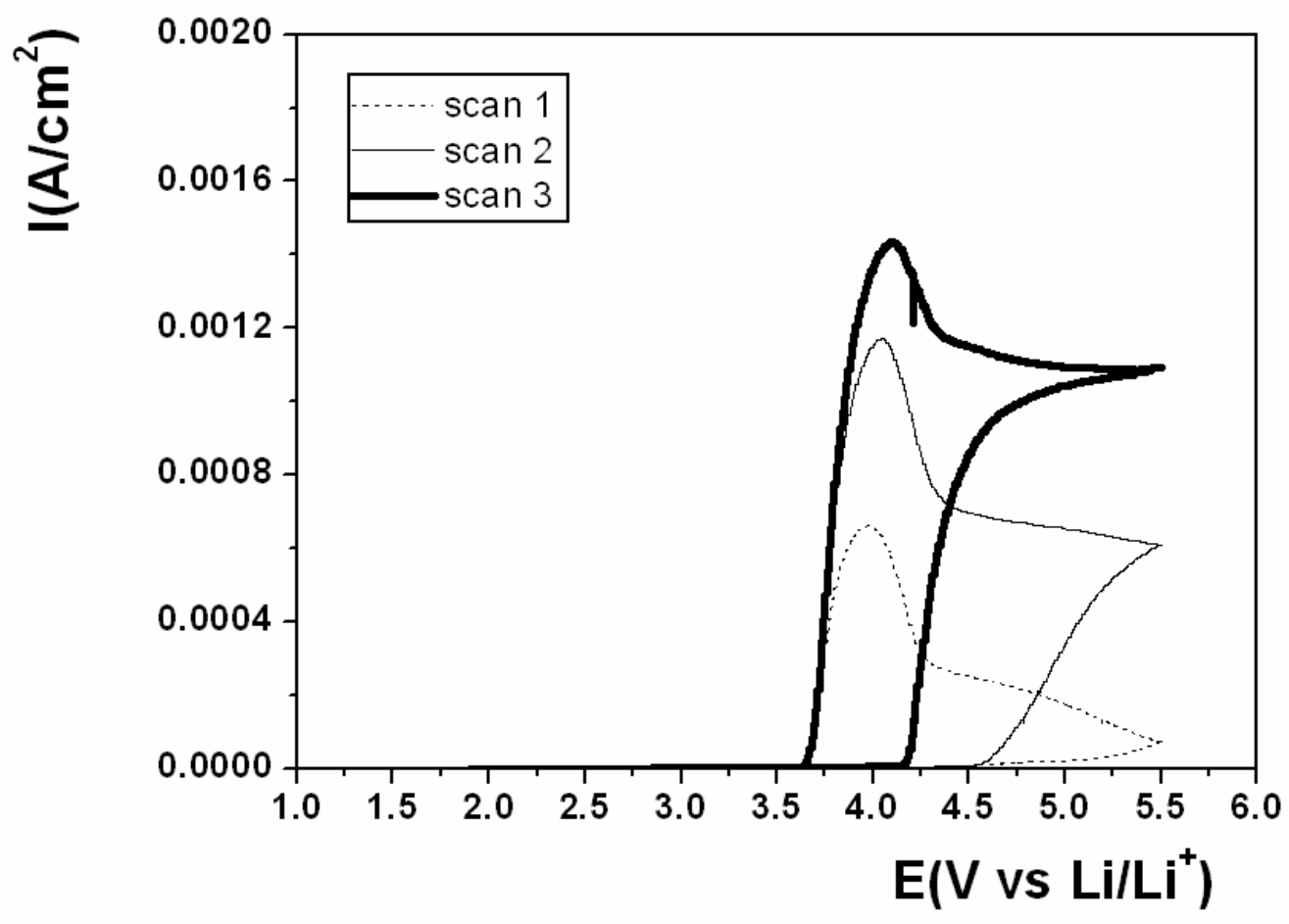

Figure 4. Three consecutive cyclic polarization curves of aluminum in 1:1 EC+DMC with 1M LiTFSI. At high potentials, the oxidation rate increases with increasing number of cycles due pitting corrosion. 


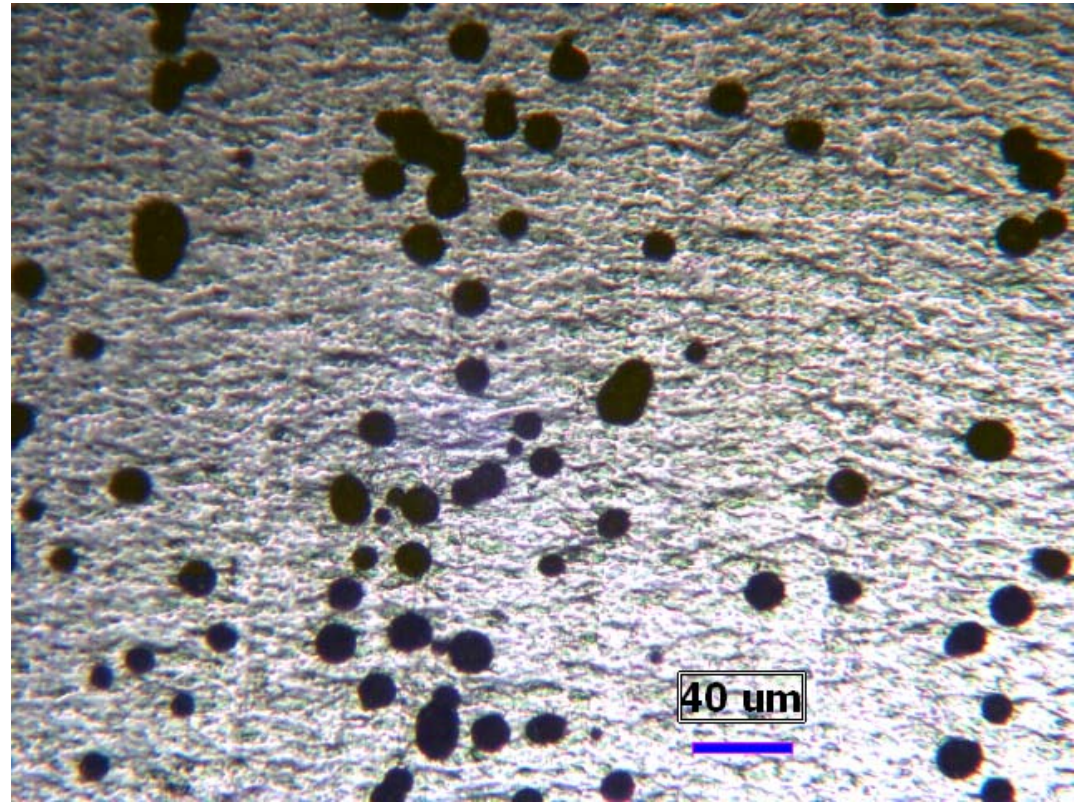

Figure 5. Optical micrograph of corrosion pits in surface of aluminum that was subjected to three cyclic polarization scans between $1.8 \mathrm{~V}$ and $5.5 \mathrm{~V}$ in $1: 1 \mathrm{EC}+\mathrm{DMC}$ with $1 \mathrm{M}$ LiTFSI. 


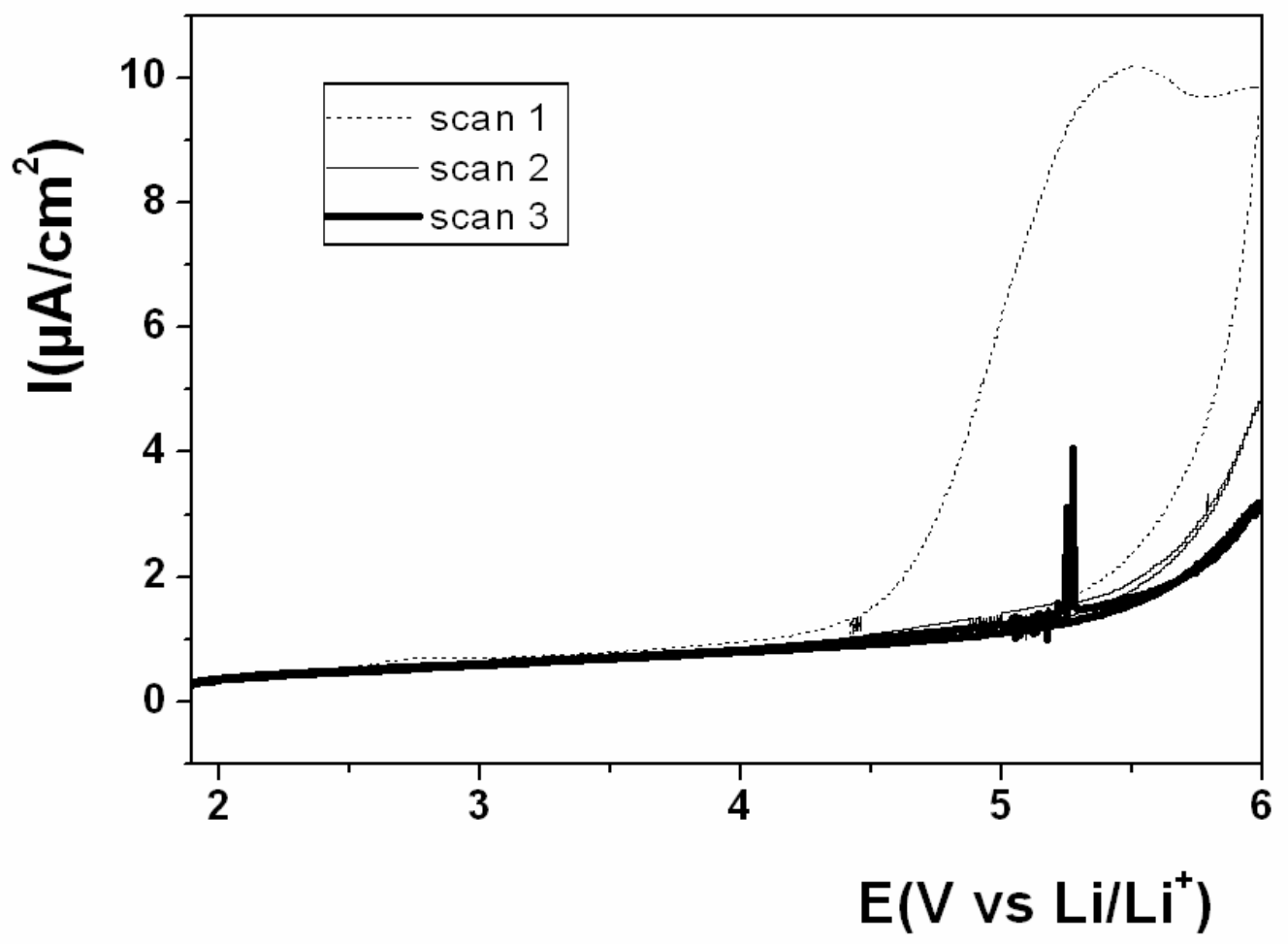

Figure 6a. Three consecutive cyclic polarization curves of aluminum in 1:1 EC+DMC with $1 \mathrm{M} \mathrm{LiBOB}$. At high potentials, the oxidation rate decreases with increasing number of cycles due to the formation of a protective film. 


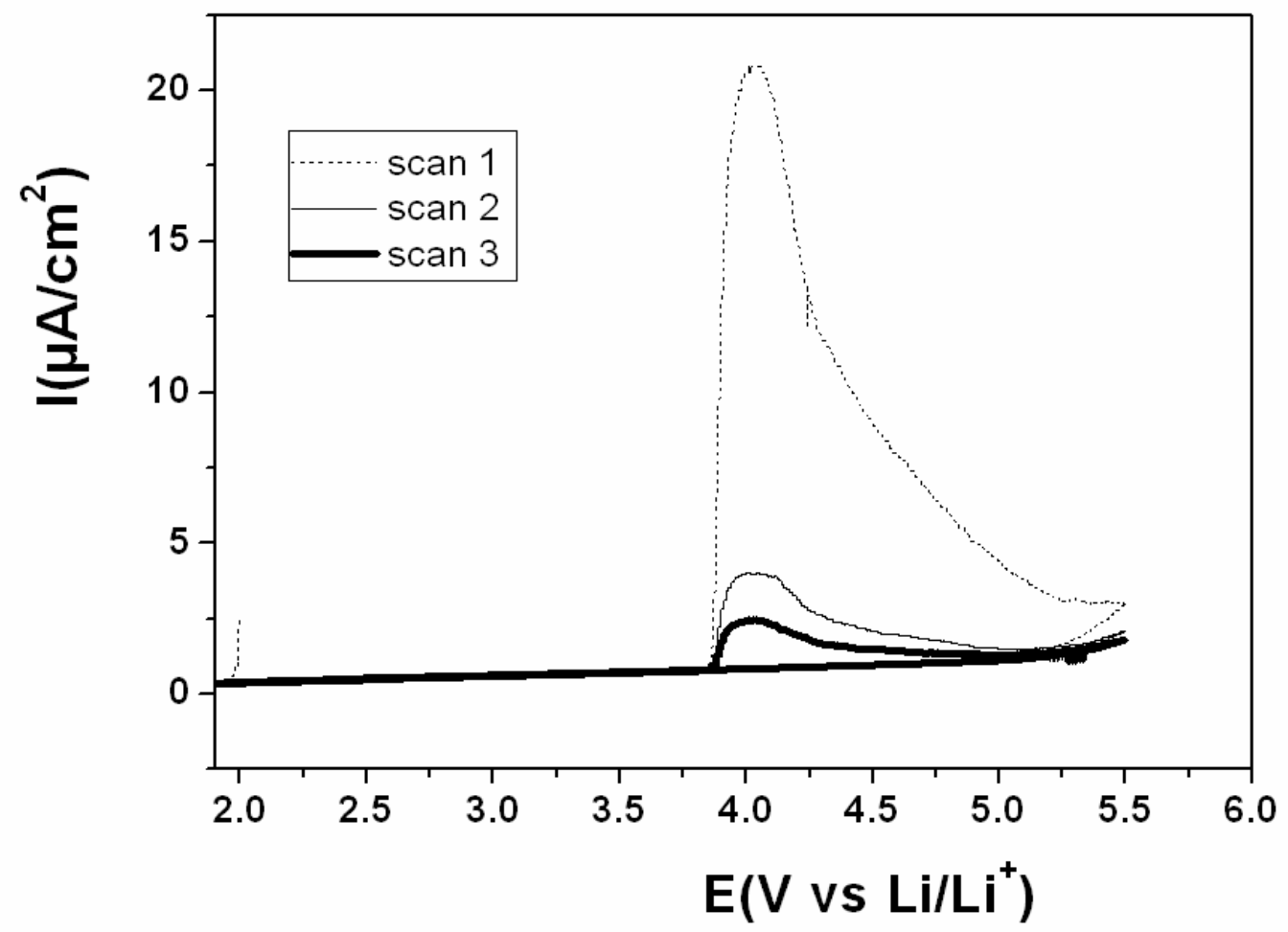

Figure $6 \mathrm{~b}$. Three consecutive cyclic polarization curves of prepassivated aluminum in 1:1 EC+DMC with 1M LiTFSI. The prepassivation treatment consisted of the three cyclic polarization scans presented in Figure 6a and produced a protective film. 


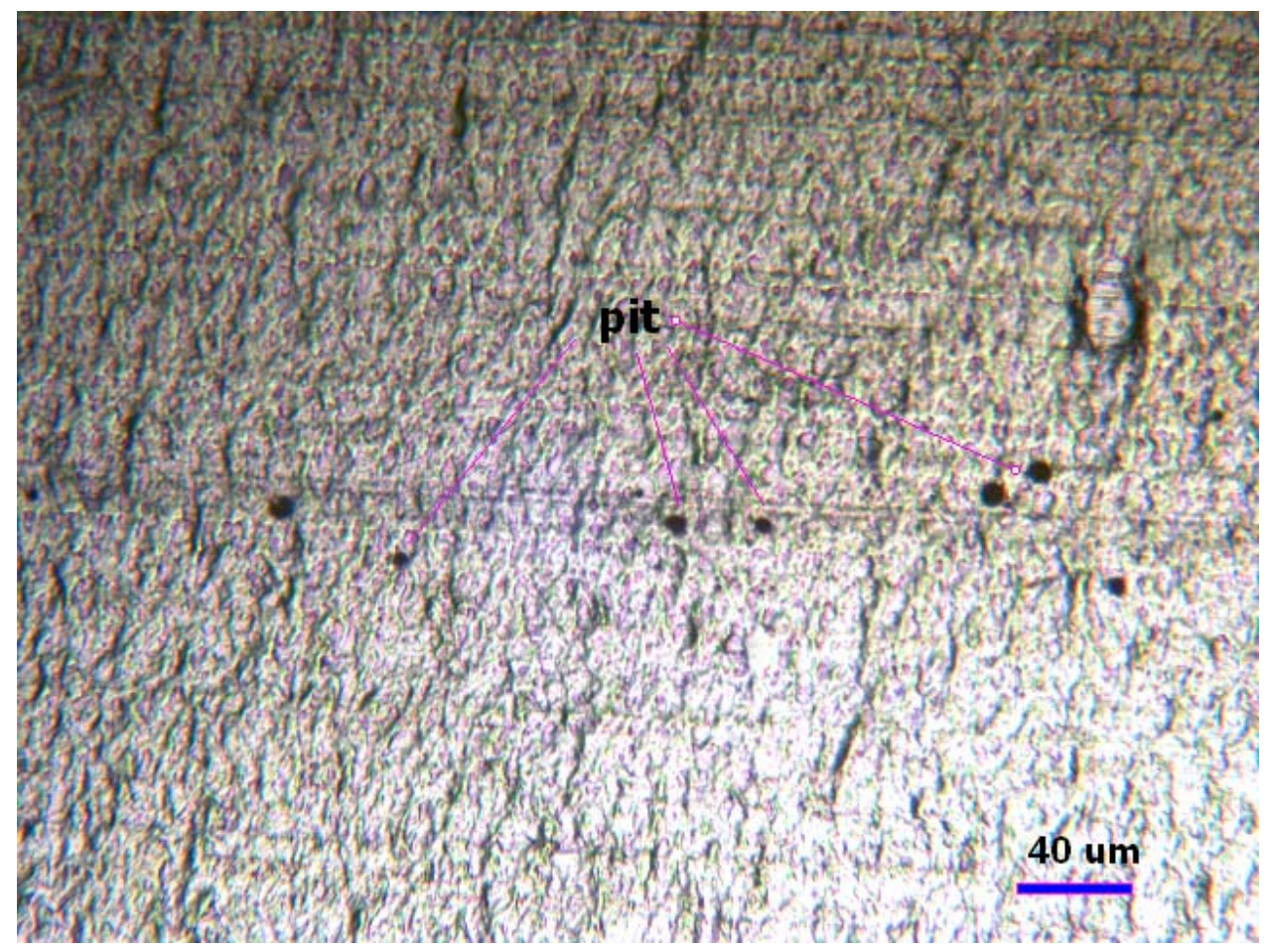

Figure 7. Optical micrograph showing the small number of corrosion pits in surface of aluminum that was first passivated by three cyclic polarizations in 1:1 EC+DMC with 1M LiBOB (see Figure 6a) and then subjected to three cyclic polarization scans in 1:1 EC+DMC with 1M LiTFSI (see Figure 6b). 


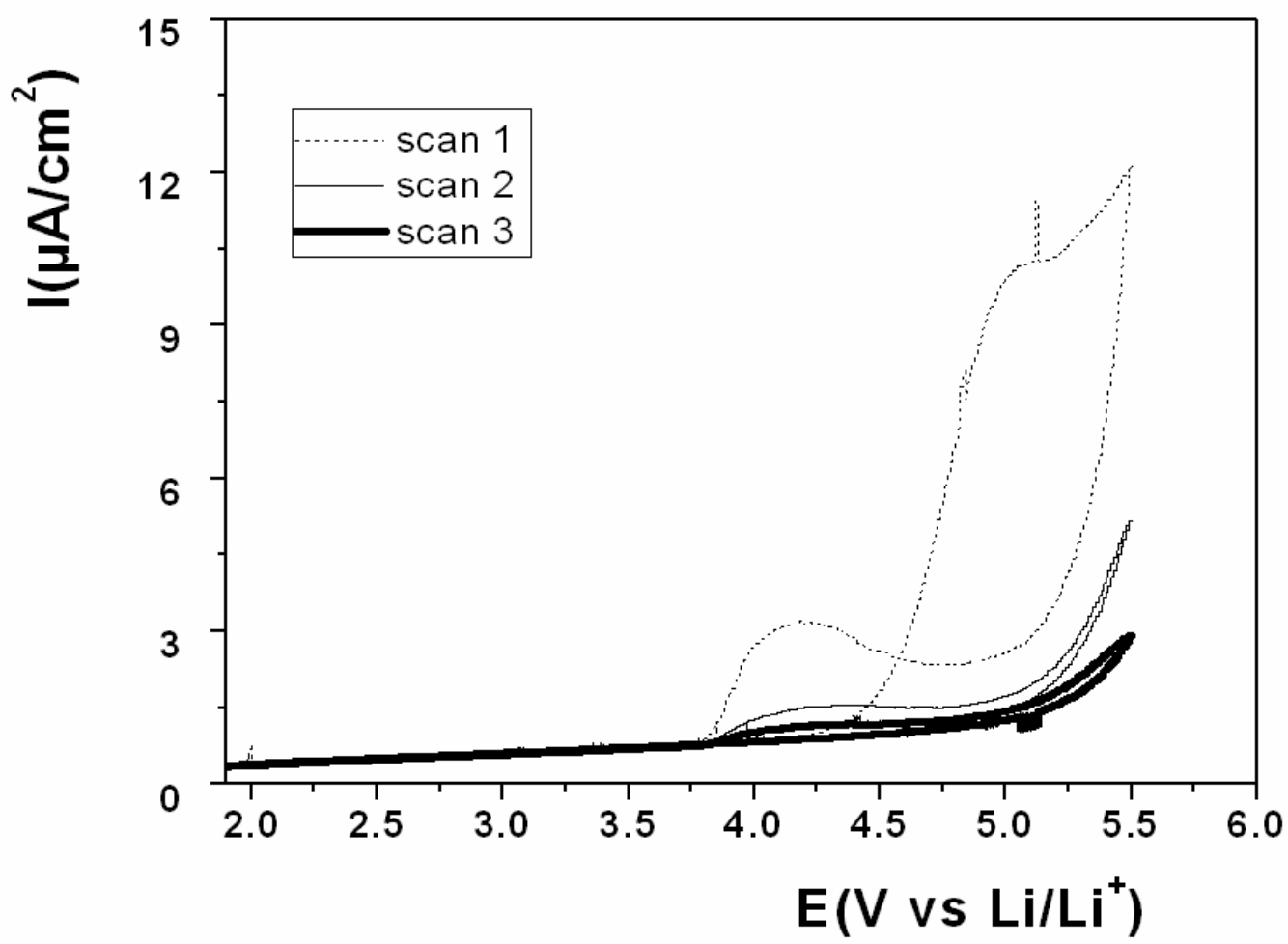

Figure 8. Three consecutive cyclic polarization curves of aluminum in 1:1 EC+DMC with 1M mixture of 9:1 LiTFSI+LiBOB. 


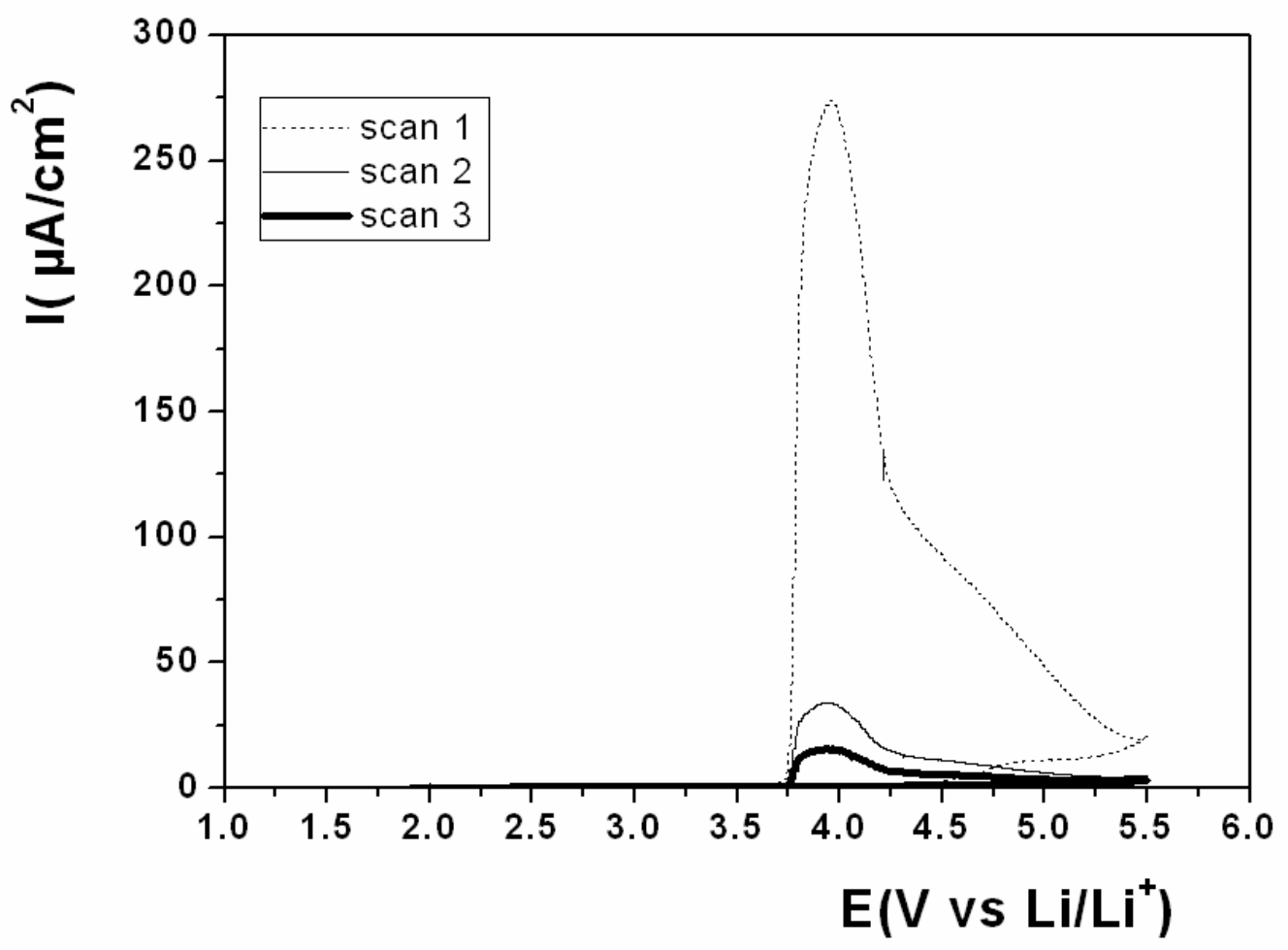

Figure 9. Three consecutive cyclic polarization curves of aluminum in 1:1 EC+DMC with 1M mixture of 98:2 LiTFSI+LiBOB. 


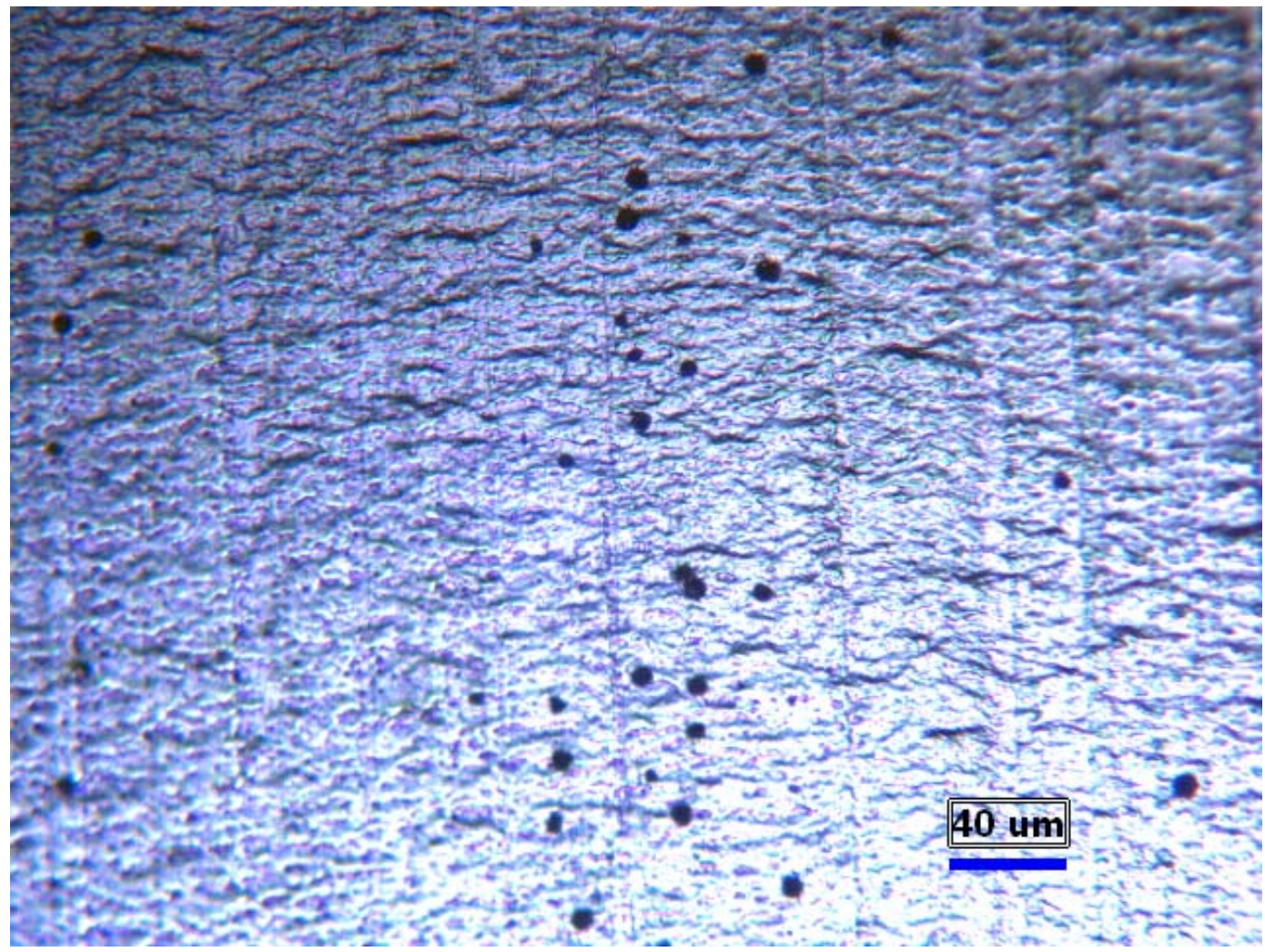

Figure10. Optical micrograph of surface of aluminum that was subjected to three cyclic polarization scans in 1:1 EC+DMC with 1M mixture of 98:2 LiTFSI+LiBOB (see Figure 9). 